\title{
Coordinating a Multi-Retailer Decentralized Distribution System with Random Demand Based on Buyback and Compensation Contracts
}

\author{
Jinyu Ren ${ }^{1,2}$, Hualong Xie ${ }^{2}$, Yongxian $\mathrm{Liu}^{2}$, Pengfei Zeng ${ }^{1}, \mathrm{Ze} \mathrm{Tao}^{1}$ \\ ${ }^{1}$ School of Mechanical Engineering, Shenyang Ligong University (China) \\ ${ }^{2}$ School of Mechanical Engineering \& Automation, Northeastern University (China) \\ rij27@163.com,_blxie@mail.neu.edu.cn,_pxlim@mail.neu.edu.cn,pfzeng@163.com,taoze@,tsingbua.edu.cn
}

Received: November 2014

Accepted: February 2015

\section{Abstract:}

Purpose: The purpose of this paper is to set up the coordinating mechanism for a decentralized distribution system consisting of a manufacturer and multiple independent retailers by means of contracts. It is in the two-stage supply chain system that all retailers sell an identical product made by the manufacturer and determine their order quantities which directly affect the expected profit of the supply chain with random demand.

Design/methodology/approach: First comparison of the optimal order quantities in the centralized and decentralized system shows that the supply chain needs coordination. Then the coordination model is given based on buyback cost and compensation benefit. Finally the coordination mechanism is set up in which the manufacturer as the leader uses a buyback policy to incentive these retailers and the retailers pay profit returns to compensate the manufacturer.

Findings: The results of a numerical example show that the perfect supply chain coordination and the flexible allocation of the profit can be achieved in the multi-retailer supply chain by the buyback and compensation contracts.

Research limitations: The results based on assumptions might not completely hold in practice and the paper only focuses on studying a single product in two-stage supply chain. 
Practical implications: The coordination mechanism is applicable to a realistic supply chain under a private information setting and the research results is the foundation of further developing the coordination mechanism for a realistic multi-stage supply chain system with more products.

Originality/value: This paper focused on studying the coordination mechanism for a decentralized multi-retailer supply chain by the joint application of the buyback and compensation contracts. Furthermore the perfect supply chain coordination and the flexible allocation of the profit are achieved.

Keywords: supply chain management, coordination model, compensation, buyback policy

\section{Introduction}

Supply chain management seems to be a growing area of interest amongst researchers and practitioners from varied disciplines. Coordination is a central lever of supply chain management (Ballou, Gilbert \& Mukherjee, 2000) and the essence of the coordination is to design an effective incentive mechanism which makes the members of supply chain achieve the total optimization in the process of independent decisions (Anderson \& Lee, 1999). Zimmer set up coordination mechanisms by the ways of two incentive schemes about penalty cost and bonus combined with order quantity respectively, and works out the optimal combined value with order quantity and bonus and with order quantity and bonus (Zimmer, 2002). Giannoccaro and Pontrandolfo (2004) proposed a model of a supply chain contract based on the revenue sharing mechanism and this model allowed the system efficiency to be achieved as well as it could improve the profits of all the SC actors by tuning the contract parameters (Giannoccaro \& Pontrandolfo, 2004). Cachon and Lariviere (2005) showed that buyback contracts and revenue-sharing contracts are equivalent in the fixed-price newsvendor model. For any buyback contract, there exists a revenue-sharing contract that generates the same cash flows for any realization of demand. However, this is not the case when demand is pricedependent (Cachon \& Lariviere, 2005). Yao et al. showed that a profit sharing contract could coordinate a decentralized supply chain in the same way as a buyback contract (Yao, Chen \& Yan, 2007). Shin and Benton developed a quantity discount model that resolved the practical challenges associated with implementing quantity discount policies for supply chain coordination between a supplier and a buyer (Shin \& Benton, 2007). Chen et al. proposed a three-parameter risk and profit sharing contract to coordinate the supply chain (Chen, Chen, Chiu, Choi \& Sethi, 2010). Jing et al. investigated a decentralized supply chain that consists of a manufacturer and a retailer where the retailer simultaneously determines the retail price and order quantity while experiencing customer returns and price dependent stochastic demand 
and proposed an agreement between the manufacturer and the retailer that includes two buyback prices (Jing \& Peter, 2011). Omkar et al. demonstrated that using revenue-dependent the revenue sharing contracts supply chains could be coordinated while providing positive surplus to the supply chain players that is otherwise not possible under certain situations in revenue -independent contracts (Omkar \& Palsule,2013). Shibaji explored coordination of a corporate social responsible manufacturer-retailer chain by setting revenue sharing contract (Shibaji, 2014).

In recent years, researchers have not only given considerable attention to the production flow synchronization of the single-vendor and single- buyer integrated inventory supply chain but also paid more attention to the synchronization of the single-vendor and multi-buyer case (Hoque, 2008; Yan, 2011; Liu, 2007; Palut \& Ulengin, 2011; Cao, Wan \& Lai, 2013). Ozen, Sosic and Slikker (2012) focused on coordination of the manufacturer and the retailers through buy-back contracts and prove buy-back contracts, in general, couldn't make the distribution system achieve the same performance as the centralized system (Ozen et al., 2012). Wu et al. studied supply chain system consisting of one supplier and multiple retailers when the demand function and cost were disrupted simultaneously, and presented a revenue sharing contract to realize anti-disruption (Wu \& Yang, 2010; Cao \& Lai, 2010).

Based on these literatures this paper considered a decentralized two-stage supply chain consisting of a manufacturer and multiple independent retailers, in which all retailers sold an identical product made by the manufacturer and determined their order quantities. The optimal order quantities in the centralized and decentralized system were compared and gave the coordination necessity for the supply chain. Then the coordination mechanism was set up in which the manufacturer as the leader uses a buyback policy to incentive these retailers and the retailers pay profit returns to compensate the manufacturer. Compared with the above mentioned literatures, it is by the buyback and compensation contracts that not only the perfect supply chain coordination but also the flexible allocation of the profit can be achieved in the multi-retailer supply chain in this paper.

The paper was organized as follows. In section 2, the basic model was discussed and the profit functions of the manufacturer and the retailer are presented. In section 3 two extreme cases of the decentralized and centralized systems are given to evaluate the coordination mechanisms in the following sections. Section 4 developed the coordination mechanism based on the buyback and compensation contracts. In section 5, a numerical example was given. The paper was concluded in Section 6. 


\section{The Basic Model}

Here consider a decentralized two-stage supply chain with a manufacturer and multiple retailers in a one-period setting. The manufacturer as the leader in the system produces and sells an identical product for the retailers at the same wholesale price. All the retailers face stochastic customer demand and have to determine his stocking quantities, which he orders from the manufacturer, at the beginning of a selling period. When placing their order, the retailers don't know exact demand realization but know the distribution of the demand. After the manufacturer shipped the goods to all the retailers and the retailers begin to sell the goods for the customers, the demand for every retailer is realized. If the ordered amount is more than the market demand so that the surplus products can not be sold at the end of the period, the retailers would salvage any leftover inventory. If the ordered amount is less than the external demand, the retailer needs to pay for the shortage cost.

\subsection{The Manufacturer Model}

We assume that the system contains $n$ retailers based on the above description. Then the manufacturer's actual profit with the decentralized decision situation is

$$
\Pi^{M}=\sum_{i=1}^{n}\left(w-c-t_{i}\right) q_{i}, i=1,2, \cdots, n
$$

\section{Notations}

$\Pi^{M}$ : Profit for the manufacturer

$q_{i}$ : Order quantity for retailer $i$

$c$ : Production cost per unit for the manufacturer

$w$ : Wholesale price per unit

$t_{i}$ : Transportation cost per unit from the manufacturer to retailer $i$, not including purchasing cost.

\subsection{The Retailer's Model}

At the end of a selling period the actual profit for retailer is

$$
\Pi^{S_{i}}=p_{i} \min \left\{q_{i}, r_{i}\right\}+s_{i}\left[q_{i}-r_{i}\right]^{+}-\pi_{i}\left[r_{i}-q_{i}\right]^{+}-w q_{i}, \quad i=1,2, \cdots, n
$$


Where $\left[q_{i}-r_{i}\right]^{+}=\left\{\begin{array}{cc}q_{i}-r_{i} & q_{i} \geq r_{i} \\ 0 & q_{i} \leq r_{i}\end{array}, \quad\left[r_{i}-q_{i}\right]^{+}=\left\{\begin{array}{cc}r_{i}-q_{i} & q_{i} \leq r_{i} \\ 0 & q_{i} \geq r_{i}\end{array}\right.\right.$.

\section{Notations}

$\Pi^{S_{i}}$ : Profit for retailer $i$

$p_{i}$ : Selling price per unit for retailer $i$

$s_{i}$ : Salvage cost per unit for retailer $i$

$\pi_{i}$ : Shortage value per unit for retailer $i$

$r_{i}$ : Market demand for retailer $i$

When the demand distribution $F\left(r_{i}\right)$ and the density function $f\left(r_{i}\right)$ for retailer $i$ are known, the expected profit for retailer $i$ is given by

$$
\begin{gathered}
E\left(\Pi^{S_{i}}\right)=p_{i} \int_{0}^{q_{i}} r_{i} f\left(r_{i}\right) d r_{i}+p_{i} \int_{q_{i}}^{\infty} q_{i} f\left(r_{i}\right) d r_{i}+S_{i} \int_{0}^{q_{i}}\left(q_{i}-r_{i}\right) f\left(r_{i}\right) d r_{i}-\pi_{i} \int_{q_{i}}^{\infty}\left(r_{i}-q_{i}\right) f\left(r_{i}\right) d r_{i} \\
-w q_{i}, \quad i=1,2, \cdots, n
\end{gathered}
$$

\section{The Coordination Necessity Analysis}

\subsection{The Decentralized Decision}

In a decentralized supply chain system, each retailer tries to optimize his own entity and the manufacturer does likewise. The manufacturer as the leader determines the wholesale price w according to the market supply and demand, and the retailers as the followers determine their optimal order quantities $q_{\text {iopt }}$ which achieves maximal expected profit according to the manufacturer's decision.

Firstly, the first derivative of the function $E\left(\Pi^{S_{i}}\right)$ on the order quantity $q_{i}$ according to Equation 3 is solved by

$$
\frac{d E\left(\Pi^{S_{i}}\right)}{d q_{i}}=p_{i} \int_{q_{i}}^{\infty} f\left(r_{i}\right) d r_{i}+s_{i} \int_{0}^{q_{i}} f\left(r_{i}\right) d r_{i}+\pi_{i} \int_{q_{i}}^{\infty} f\left(r_{i}\right) d r_{i}-w
$$


Then the second derivative of the function $E\left(\Pi^{S_{i}}\right)$ on the order quantity $q_{i}$ according to Equation 4 is solved by

$$
\frac{d^{2} E\left(\Pi^{S_{i}}\right)}{d q_{i}^{2}}=\left(-p_{i}-\pi_{i}+s_{i}\right) f\left(q_{i}\right)
$$

Because the salvage cost for retailer $i$ must be less than the selling price for retailer $i$, viz. $p_{i} s_{i}$, and $f\left(q_{i}\right) \quad 0$, the expected profit for retailer $i E\left(\Pi^{S_{i}}\right)$ must have maximum value. Then let the first derivative of the function $E\left(\Pi^{S_{i}}\right)$ on the order quantity $q_{i}$ equal zero, viz. $\frac{d E\left(\Pi^{S_{i}}\right)}{d q_{i}}=0$, and the optimal order quantity $q_{\text {iopt }}$ can be solved by

$$
F\left(q_{\text {iopt }}\right)=\left(\pi_{i}+p_{i}-w\right) /\left(\pi_{i}+p_{i}-s_{i}\right)
$$

\subsection{The Centralized Decision}

In the centralized system, there is a single maker who tries to optimize the overall supply chain and the optimal decision which can allow the supply chain system to achieve the maximal overall expected profit is determined as a joint optimal problem.

So the actual total profit of the supply chain is given by

$$
\Pi^{T C}=\sum_{i=1}^{n}\left(p_{i} \min \left\{q_{i}, r_{i}\right\}+\max \left\{\left\{_{i}, h-t_{i}\right\}\left[q_{i}-r_{i}\right]^{+}-\pi_{i}\left[r_{i}-q_{i}\right]^{+}\right)-\sum_{i=1}^{n}\left(c+t_{i}\right) q_{i}\right.
$$

Where $h$ stands for the unit price that the manufacturer handles with the unsold products at the end of the period.

When the demand distribution $F\left(r_{i}\right)$ and the density function $f\left(r_{i}\right)$ for all the retailers are known, the expected total profit for the supply chain $E\left(\Pi^{T C}\right)$ is given by

$$
\begin{gathered}
E\left(\Pi^{T C}\right)=\sum_{i=1}^{n}\left(p_{i} \int_{0}^{q_{i}} r_{i} f\left(r_{i}\right) d r_{i}+p_{i} \int_{q_{i}}^{\infty} q_{i} f\left(r_{i}\right) d r_{i}+\max \left\{s_{i}, h-t_{i}\right\} \int_{0}^{q_{i}}\left(q_{i}-r_{i}\right) f\left(r_{i}\right) d r_{i}-\right. \\
\left.\pi_{i} \int_{q_{i}}^{\infty}\left(r_{i}-q_{i}\right) f\left(r_{i}\right) d r_{i}\right)-\sum_{i=1}^{n}\left(c+t_{i}\right) q_{i}
\end{gathered}
$$

Based on Equation 8, the first partial derivative of the function $E\left(\Pi^{T C}\right)$ on the order quantity $q_{i}$ for retailer $i$ is solved by

$$
\frac{\partial E\left(\Pi^{T C}\right)}{\partial q_{i}}=p_{i} \int_{q_{i}}^{\infty} f\left(r_{i}\right) d r_{i}+\max \left\{s_{i}, h-t_{i}\right\} \int_{0}^{q_{i}} f\left(r_{i}\right) d r_{i}+\pi_{i} \int_{q_{i}}^{\infty} f\left(r_{i}\right) d r_{i}-\left(c+t_{i}\right) \quad i=1,2, \cdots, n
$$


Then the second partial derivative of the function $E\left(\Pi^{T C}\right)$ on the order quantity $q_{i}$ according to Equation 9 is solved by

$$
\frac{\partial^{2} E\left(\Pi^{T C}\right)}{\partial q_{i}^{2}}=\left(-p_{i}-\pi_{i}+\max \left\{s_{i}, h-t_{i}\right\}\right) f\left(q_{i}\right) \quad i=1,2, \cdots, n
$$

Obviously, the same with the decentralized decision situation, viz. $\frac{\partial^{2} E\left(\Pi^{T C}\right)}{\partial q_{i}^{2}} \geq 0$, which shows that the function $E\left(\Pi^{T C}\right)$ must have maximum value. Then let the first derivative of the function $E\left(\Pi^{T C}\right)$ on the order quantity $q_{i}$ equal zero, viz. $\frac{\partial E\left(\Pi^{T C}\right)}{\partial q_{i}}=0$, and the optimal order quantity $q_{\text {iopt }}^{C}$ with centralized decision situation can be solved by,

$$
F\left(q_{i o p t}^{C}\right)=\frac{\pi_{i}+p_{i}-c-t_{i}}{\pi_{i}+p_{i}-\max \left\{s_{i}, h-t_{i}\right\}} \quad i=1,2, \cdots, n
$$

\subsection{The Coordination Necessity}

Comparing Equation 6 with Equation 11, it is known that the wholesale price charged the manufacturer is more higher than the sum of production cost and transportation cost, i.e. $w>c+t_{i}$, and $s_{i} \leq \max \left\{s_{i}, h-t_{i}\right\}$. At the same time the demand distribution function $F\left(r_{i}\right)$ is an increasing function. Therefore, the more order quantity with centralized decision scenario will be placed by every retailer than with decentralized decision scenario. In addition, the expected profit of the supply chain mainly depends on the order quantity of the retailers and increases with improving the order quantity. From that it can be deduced that the centralized decision will leads to a higher total profit for the entire supply chain.

Therefore in order to allow the decentralized system to achieve the same performance as a centralized supply chain and make the retailers actively participate in cooperation, the manufacturer as the leader in supply chain needs to set up a coordination mechanism based on contracts to ensure that the expected profit for the retailers will be higher than with the decentralized decision situation.

\section{The Coordination Mechanism}

In general, salvaging at the manufacturer is more beneficial than salvaging at the retailer because the manufacturer might redirect the unsold or not-needed units to this market and gain the positive revenue. In order to allow the decentralized system to achieve the same performance as a centralized supply chain, the manufacturer as the leader of the game should 
buy back the unsold products for every retailer at the end of period. But only buyback contract, in general, cannot make the distribution system achieve the same performance as the centralized system (Ozen et al., 2012). Therefore the manufacturer should guide the retailers to give up opposition in the buyback process to achieve revenue sharing through the compensation contract.

Here introduces incentive functions consisting of buyback cost and compensation benefit, that is

$$
\Theta_{i}=\left\{\begin{array}{cc}
-k_{i}\left(q_{i}-r_{i}\right)+A_{i} & r_{i} \leq q_{i} \\
0 & r_{i} \geq q_{i}
\end{array} \quad i=1,2 \cdots, n\right.
$$

Where $k_{i}\left(q_{i}-r_{i}\right)$ is the cost that the manufacturer buys back the unsold units for retailer $i$ and $k_{i}$ stands for buyback cost per unit, $A_{i}$ stands for the compensation benefit that retailer $i$ pays for the manufacturer.

The actual profit of the manufacturer and retailer $i$ after introducing the incentive function is given by

$$
\begin{gathered}
\Pi^{M h}=\sum_{i=1}^{n}\left\{\left[\left(w-c-t_{i}\right) q_{i}+\left(h-k_{i}-t_{i}\right)\left[q_{i}-r_{i}\right]^{+}+A_{i}\right\}\right. \\
\Pi^{s_{i} h}=p_{i} \min \left\{q_{i}, r_{i}\right\}-\pi_{i}\left[r_{i}-q_{i}\right]^{+}+k_{i}\left[q_{i}-r_{i}\right]^{+}-w q_{i}-A_{i} \quad i=1,2 \cdots, n
\end{gathered}
$$

The two objective functions above show that the incentive function has only an indirect impact on the total cost of the supply chain, because in the functions $\left(\Pi^{M h}-\sum_{i=1}^{n} \Pi^{s_{i} h}\right)$ the expenditures of the manufacturer $\sum_{i=1}^{n}\left(k_{i}\left[q_{i}-r_{i}\right]^{+}-A_{i}\right)$ and the receipts of all the retailers $\sum_{i=1}^{n}\left(k_{i}\left[q_{i}-r_{i}\right]^{+}-A_{i}\right)$ cancel each other out.

When the distribution of the demand $F\left(r_{i}\right)$ for all the retailers is known, the expected profit of the manufacturer and retailer $i$ are given by

$$
\begin{gathered}
E\left(\Pi^{M h}\right)=\sum_{i=1}^{n}\left\{\left(w-c-t_{i}\right) q_{i}+\sum_{i=1}^{n}\left(h_{i}-k_{i}-t_{i}\right) \int_{0}^{q_{i}}\left(q_{i}-r_{i}\right) f\left(r_{i}\right) d r_{i}+A_{i} \int_{0}^{q_{i}} f\left(r_{i}\right) d r_{i}\right\} \\
E\left(\Pi^{S_{i} h}\right)=p_{i} \int_{0}^{q_{i}} r_{i} f\left(r_{i}\right) d r_{i}+p_{i} \int_{q_{i}}^{\infty} q_{i} f\left(r_{i}\right) d r_{i}-\pi_{i} \int_{q_{i}}^{\infty}\left(r_{i}-q_{i}\right) f\left(r_{i}\right) d r_{i}+k_{i} \int_{0}^{q_{i}}\left(q_{i}-r_{i}\right) f\left(r_{i}\right) d r_{i} \\
-A_{i} \int_{0}^{q_{i}} f\left(r_{i}\right) d r_{i}-w q_{i}
\end{gathered}
$$


According to Equation 14 solving the first partial derivative of the function $E\left(\Pi^{S_{i} h}\right)$ on the order quantity $q_{i}$ and letting it equal zero, retailer $i$ determines the optimal order quantity $q_{i o p t}^{h}$ that achieves maximal expected profit. The optimal order quantity can be calculated solving the following equation,

$$
F\left(q_{i o p t}^{h}\right)=\frac{\pi_{i}+p_{i}-w+A_{i} f\left(q_{\text {iopt }}^{h}\right)}{\pi_{i}+p_{i}-k_{i}}
$$

Assume that the buy-back price $k_{i}$ and compensation benefit $A_{i}$ decisions of the manufacturer and the retailers aim to achieve the higher total profit of the supply chain. To ensure that all the retailer chooses this value of order quantity that incurs overall maximal expected total profit, the manufacturer must fix the buy-back cost $k_{i}$ and compensation benefit $A_{i}$ so that the following equation holds:

$$
F\left(q_{\text {iopt }}^{h}\right)=F\left(q_{\text {iopt }}^{C}\right) \Leftrightarrow \frac{\pi_{i}+p_{i}-w+A_{i} f\left(q_{i o p t}^{h}\right)}{\pi_{i}+p_{i}-k_{i}}=\frac{\pi_{i}+p_{i}-c-t_{i}}{\pi_{i}+p_{i}-\max \left\{s_{i}, h-t_{i}\right\}}
$$

Assume the special case that the random variable $r_{i}$ follows a uniform distribution over the range $\left[r_{i 1}, r_{i 2}\right]$, the optimal buy-back cost $k_{i}$ as a function of compensation benefit $A_{i}$ for retailer $i$ is attained by solving Equation 18:

$$
k_{\text {iopt }}=\pi_{i}+p_{i}-\frac{\left[\left(\pi_{i}+p_{i}-w\right)\left(r_{i 2}-r_{i 1}\right)+A_{i}\right]\left[\pi_{i}+p_{i}-\max \left\{h-t_{i}, s_{i}\right\}\right]}{\left(\pi_{i}+p_{i}-c_{i}\right)\left(r_{i 2}-r_{i 1}\right)}
$$

Each combination of the buy-back cost $k_{i}$ and the compensation benefit $A_{i}$ that satisfies the above equation ensures that all the retailers choose the overall optimal order policy that leads to maximal expected total profit of the entire supply chain.

In order to make the parties of the supply chain agree to such a collaboration model, after introducing the incentive methods the expected profits of the manufacturer and the retailers should be more than that with supply chain decentralized decision situation which require to fulfill the constraints as follow,

$$
\text { s.t. }\left\{\begin{array}{c}
E\left(\Pi^{M h}\right) \geq E\left(\Pi^{M}\right) \\
E\left(\Pi^{S_{i} h}\right) \geq E\left(\Pi^{S_{i}}\right), i=1,2 \cdots, n
\end{array}\right.
$$

So far, it have been developed that collaboration mechanisms that gain an overall optimal performance of the entire supply chain. 


\section{Numerical Examples}

Here consider a supply chain with a manufacturer and two independent retailers. All parameters are specified randomly while creating the data set and the data set is satisfied with parameters constraints in the models above. Let $w=1000, c=300, h=600, t_{1}=50, t_{2}=30$, $p_{1}=1500, p_{2}=1400, \pi_{1}=1200, \pi_{2}=1000, s_{1}=500, s_{2}=450$. Assume that the market demand of two retailers follow a uniform distribution, viz. $r_{1} \in[100,200]$ and $r_{2} \in[200,300]$. Thus the continuous probability distributions of two retailers are respectively attained by

$$
\begin{gathered}
F\left(r_{1}\right)=\left\{\begin{array}{cc}
\frac{r_{1}-100}{200-100} & 100 \leq r_{1} \leq 200 \\
0 & \text { others }
\end{array}\right. \\
F\left(r_{2}\right)=\left\{\begin{array}{cc}
\frac{r_{2}-200}{300-200} & 200 \leq r_{2} \leq 300 \\
0 & \text { others }
\end{array}\right.
\end{gathered}
$$

Substituting the density functions (21) and (22) in Equation 6, the optimal order quantities of two retailers in supply chain decentralized decision scenario can be respectively determined to be

$$
\begin{aligned}
& \frac{q_{1 o p t}-100}{200-100}=\frac{\pi_{1}+p_{1}-w}{\pi_{1}+p_{1}-s_{1}} \\
& \frac{q_{2 o p t}-200}{300-200}=\frac{\pi_{2}+p_{2}-w}{\pi_{2}+p_{2}-s_{2}}
\end{aligned}
$$

After that, the optimal order quantity $q_{1 o p t}$ is 177 units and $q_{2 o p t}$ is 272 units. Based on the optimal order quantities solved the actual profit of the manufacturer is $\Pi^{M}=297290$ (see Equation 1), the expected profits of two retailer are respectively $E\left(\Pi^{S_{1}}\right)=55681$ and $E\left(\Pi^{S_{2}}\right)$ $=80256$ (see Equation 3). Then the expected total profit for the entire supply chain can be calculated, viz. $E\left(\Pi^{T}\right)=433227$. On the other hand, the optimal order quantities of two retailers in centralized decision scenario are respectively $q_{1 \text { opt }}^{C}=209$ and $q_{2 o p t}^{C}=317$ units (see Equation 11), which achieves maximal expected profit for the entire supply chain, that is $E\left(\Pi^{T C}\right)=467880$ (see Equation 8 ). The results are summarized in Table 1, which shows the expected total profit of the entire supply chain in supply chain centralized decision scenario is more than in supply chain decentralized decision scenario. Therefore, it is necessary to set up coordination mechanism to increase the total profit of the entire supply chain. 


\begin{tabular}{|l|c|c|c|c|c|c|}
\hline Parameters & $q_{1 \mathrm{opt}}$ & $q_{2 \mathrm{ppt}}$ & $\Pi^{M}$ & $E\left(\Pi^{S_{1}}\right)$ & $E\left(\Pi^{S_{2}}\right)$ & $E\left(\Pi^{T}\right)$ \\
\hline Decentralized decision & 177 & 272 & 297290 & 55681 & 80256 & 433227 \\
\hline Centralized decision & 209 & 317 & - & - & - & 467880 \\
\hline
\end{tabular}

Table 1. Decentralized Decision Compared with Centralized Decision

Firstly, according to Equation 19 the optimal buy-back cost $k_{i}$ as a function of compensation benefit $A_{i}$ for retailer $i$ is

$$
\begin{aligned}
& k_{1 \text { opt }}=\frac{26900000-215 A_{1}}{23500} \\
& k_{2 o p t}=\frac{24060000-183 A_{2}}{20700}
\end{aligned}
$$

Then according to Equation 20 the solved constraints are

$$
\text { s.t. }\left\{\begin{array}{c}
E\left(\Pi^{M h}\right) \geq 297290 \\
E\left(\Pi^{S_{1} h}\right) \geq 55681 \\
E\left(\Pi^{S_{2} h}\right) \geq 80256
\end{array}\right.
$$

Furthermore according to Equation 15 and Equation 16 the range of compensation benefit $A_{1}$ and $A_{2}$, which two retailers pays for the manufacturer, are determined by

$$
A_{1} \leq 28090, A_{1} \leq 19229 \text {, and } A_{1}+A_{2} 15468
$$

\begin{tabular}{|c|c|c|c|c|c|c|c|}
\hline$A_{1}$ & $A_{2}$ & $k_{1}$ & $k_{2}$ & $E\left(\Pi^{M h}\right)$ & $E\left(\Pi^{S_{1} h}\right)$ & $E\left(\Pi^{S_{2} h}\right)$ & $E\left(\Pi^{T h}\right)$ \\
\hline 18000 & 19200 & 980 & 992 & 331796 & 55820 & 80264 & 467880 \\
\hline 16000 & 18000 & 998 & 1003 & 326797 & 58882 & 82201 & 467880 \\
\hline 12000 & 15000 & 1034 & 1028 & 315998 & 65006 & 86876 & 467880 \\
\hline 9000 & 12000 & 1062 & 1056 & 308470 & 67658 & 91752 & 467880 \\
\hline
\end{tabular}

Finally in the range of allowable compensation benefit the optimal combination values about the buy-back cost and compensation benefit are given in Table 2.

Table 2. Optimal Combination Values about Buy-back Cost and Compensation Benefit

Table 2 indicates that the optimal combination values about the buy-back cost and compensation benefit in the range of allowable compensation benefit not only allows the expected total profit for the supply chain with the decentralized decision is same as with the centralized decision but also makes two retailers in supply chain have the higher expected 
profit than the initial expected profit and the manufacturer has no lower expected profit than the profit with the decentralized solution. Final determination on the buy-back cost and compensation benefit depends on their negotiation to realize revenue sharing. Generally, the manufacturer as the leader maintains the principle of making the retailers willing to cooperate and achieving maximum self-profit.

\section{Conclusions}

The paper considers a decentralized two-stage supply chain consisting of a manufacturer and multiple independent retailers. All retailers sell an identical product made by the manufacturer and determine their order quantities which directly affect the expected profit of the supply chain. First we compares the decentralized system, where no information exchange among the parties takes place, with the centralized system, where all decisions could be chosen simultaneously by the manufacturer, and comparison result shows that the expected total profit of the entire supply chain with the decentralized decision is always lower than the centralized decision. Therefore it is necessary for the decentralized distribution supply chain to set up the coordination mechanism to perform as well as the centralized one.

Then the coordination mechanism is given in which the manufacturer as the leader of the game, on the one hand, buys back the unsold products for every retailer at the end of period to incentive these retailers, on the other hand, guides the retailers to give up opposition in the buyback process to achieve revenue sharing through the compensation contract. Finally, the results of a numerical example show that the perfect supply chain coordination and the flexible allocation of the profit can be achieved in the multi-retailer decentralized distribution supply chain by the buyback and compensation contracts.

The paper might have some limitations. First the results based on assumptions might not completely hold in practice. But it can be shown that the coordination mechanism is also applicable to a realistic supply chain under a private information setting. Second the paper only focuses on studying a single product in two-stage supply chain. Thus it would be worth developing such the coordination mechanism for the multi-stage supply chain system with more products.

\section{Acknowledgement}

Supported by National Science \& Technology Support Program Project (2012BAF12B08-04), Liaoning Province Science and Technology Key Project (2011216010), Program for Liaoning Excellent Talents in University (No. LJQ2012019) and the education department of Liaoning Province (L2012067). 


\section{References}

Anderson, D., \& Lee, H. (1999). Synchronized Supply Chains: The New Frontier[J]. ASCET, 6(1). http://www.ascet.com

Ballou, R.H., Gilbert, S.M., \& Mukherjee, A. (2000). New managerial challenges from supply chain opportunities. Industrial Marketing Management, 29(1), 7-18.

http://dx.doi.org/10.1016/S0019-8501(99)00107-8

Cao, E.B., Wan, C., \& Lai, M.Y. (2013). Coordination of a supply chain with one manufacturer and multiple competing retailers under simultaneous demand and cost disruptions. Int. J. Production Economics, 141, 425-433. http://dx.doi.org/10.1016/j.ijpe.2012.09.009

Cachon, G.P., \& Lariviere, M.A. (2005). Supply chain coordination with revenue sharing contracts: strengths and limitations. Management Science, 51(1), 30-44. http://dx.doi.org/10.1287/mnsc. 1040.0215

Chen, H., Chen, Y., Chiu, C., Choi, T., \& Sethi, S. (2010). Coordination mechanism for the supply chain with leadtime consideration and price-dependent demand. European Journal of Operational Research, 203(1), 70-80. http://dx.doi.org/10.1016/j.ejor.2009.07.002

Cao, E.B., \& Lai, Y.M. (2010). Coordination mechanism of supply chain including multiple retailers when demand and cost are disrupted. System Engineering-Theory \& Practice, 30, $1752-1761$.

Giannoccaro, I., \& Pontrandolfo, P. (2004). Supply chain coordination by revenue sharing contracts. Production Economics, 89, 131-139. http://dx.doi.org/10.1016/S0925-5273(03)00047-1

Hoque, M.A. (2008). Synchronization in the single-manufacturer multi-buyer integrated inventory supply chain. European Journal of Operational Research, 188(3), 811-825. http://dx.doi.org/10.1016/j.ejor.2007.05.019

Jing, C., \& Peter, C.B. (2011). Coordinating a decentralized supply chain with customer returns and price-dependent stochastic demand using a buyback policy. European Journal of Operational Research, 1-8.

Liu, C.L. (2007). Contract coordination of supply chain system based on multi-retailers. Journal of Management Science in China, 10, 1-6. http://dx.doi.org/10.1007/s11430-007-6023-0

Ozen, U., Sosic, G., \& Slikker, M. (2012). A collaborative decentralized system with demand forecast updates. European Journal of Operational Research, 216(3), 573-583.

http://dx.doi.org/10.1016/j.ejor.2011.07.055

Omkar, D., \& Palsule, D.(2013). Supply chain coordination using revenue-dependent revenue sharing contracts. Omega, 41, 780-796. http://dx.doi.org/10.1016/j.omega.2012.10.001 
Palut, P.T., \& Ulengin, F. (2011). Coordination in a two-stage capacitated supply chain with multiple suppliers. European Journal of Operational Research, 212, 43-53.

http://dx.doi.org/10.1016/j.ejor.2011.01.018

Shin, H., \& Benton, W.C. (2007). A quantity discount approach to supply chain coordination. European Journal of Operational Research, 180(2), 601-616.

http://dx.doi.org/10.1016/j.ejor.2006.04.033

Shibaji, P. (2014). Coordination of a socially responsible supply chain using revenue sharing contract. Transportation Research Part E, 67, 92-104. http://dx.doi.org/10.1016/j.tre.2014.04.002

Wu, X.J., \& Yang, Z.H (2010). Coordinating Multiple Retailers Supply Chains When Cost and Demand are Disrupted. Journal of Hunan University (Natural Sciences), 35(5), 88-92.

Yan, R.L. (2011). Managing channel coordination in a multi-channel manufacturer-retailer supply chain. Industrial Marketing Management, 60, 636-642.

http://dx.doi.org/10.1016/j.indmarman.2010.12.019

Yao, L., Chen, Y., \& Yan, H. (2007). Analysis of a supply contract for coordinating with price dependent demand. Working paper, Chinese University of Hong Kong.

Zimmer, K. (2002). Supply chain coordination with uncertain just-in-time delivery. Production Economics, 77, 1-15. http://dx.doi.org/10.1016/S0925-5273(01)00207-9

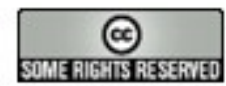

Article's contents are provided on a Attribution-Non Commercial 3.0 Creative commons license. Readers are allowed to copy, distribute and communicate article's contents, provided the author's and Journal of Industrial Engineering and Management's names are included. It must not be used for commercial purposes. To see the complete license contents, please visit http://creativecommons.org/licenses/by-nc/3.0/. 